\title{
Information Finding for Self-directed Learning and Professional Development: Perceptions and Practices of Business Professionals
}

\author{
Abdus Sattar Chaudhry \\ College of Social Sciences, Kuwait University
}

\begin{abstract}
Potential of social media was reviewed for professional development focusing on self-directed learning Business professionals working in Kuwaiti companies reported that they tried to exploit social software and networking sites for building and maintaining personal networks. They regularly commented on postings of their contacts and reflected on writings on blogs and wiki edits to strengthen their learning networks. Collaboration with counterparts in other companies was considered helpful for information finding and professional development.
\end{abstract}

\section{Introduction}

Work environment in business organizations is very competitive. In these organizations capabilities of professionals are constantly reviewed comparing with their peers. Among other things, this could be because of emerging technologies, increasing customer demands or changed vision of new management. As a results, business professionals need to keep them abreast with the new information to protect their employability. They need to learn new things to keep up with the new trends. Aldridge and Hughes [1] suggest that there is a strong correlation between learning and sustained employment.

Business professionals who undertake learning activities are able to adapt to the changing requirements. This helps them gain a competitive edge in the job market. When they demonstrate their interest about their professional development, business professionals are likely to be seen as highly motivated and engaged. Openness to learning is an indicator of flexibility and adaptability. This brings a continuous improvement ethos to the workplace. Continuing professional development is the means by which business professionals can maintain their knowledge and skills. It is important to help ensure competence to practice taking advantage of formal, informal, structured, and self-directed learning.

Manning [2] states that self-directed learning implies a lifelong education. Candy [3] points out that the relationship between self-directed learning and lifelong education is a reciprocal one. It is one of the most common way in which people supplement learning received in formal settings. It is helpful in equipping people with skills and competencies required to continue their own education.
Cross [4] stated that a powerful way to promote connectivity in an organization is to work through the personal networks of employees. People tend to be successful in very diverse entrepreneurial networks. Anklam [5] considered the emergence of social media and social networking services critical learning and professional development. There is an increased emphasis on social networks as being a primary focus for learning and development. To exploit social media and ensure successful collaboration, professionals should be able to make sense of the plethora of social media tools, sites, and Web applications. Chaudhry [6] highlighted the potential of blogs, wikis, and social media in keeping up with new trends. He highlighted that active participation and reflection on blogs and other social media can help build and strengthen personal networks that can turn into learning networks. Professionals who are active on social networking and social media are more information literate and therefore more productive at work.

This paper reviews the continuing education activities of business professionals working in Kuwaiti companies. The paper focuses on three aspects of continuing education: information finding practices and preferences for information sources focusing on use of social media. The paper focused on use of social media for self- directed learning and professional development and continuing education, particularly building and strengthening personal networks for learning. Data for this study was collected through an online questionnaire from 53 business professionals from 17 companies in different sectors of economy. The term business professionals is used in this paper to refer to those employees who hold positions involving different types of financial tasks in business enterprises.

\section{Data Collection}

A list of business professionals was compiled using directories of companies and sources from the Kuwait Chamber of Commerce \& Industry. All professionals holding a minimum of a bachelor degree in their area of work and currently handling professional assignments were invited to participate in the study. Initial response was not very encouraging but with reminders and follow up data were provided by 53 professionals. They were asked how did they initiate information finding for work 
tasks and what information sources they preferred. They also provided information about identification of contacts for building personal networks and activities performed on regularly bases on social media and networking sites to strengthen learning networks for continuing education and professional development.

\section{Findings}

Business professionals who participated in this study, considered company information as the most important among their information needs and included the following as other types of information required to support their work: information on countries, investment opportunities, and projects and business owners.

Participants also reported that collaboration with professionals working in other companies is important to access information sources necessary for keeping their knowledge up to date. These findings have implications for information collection and management policies for relevant departments in business organizations.

\subsection{Information Finding Approaches}

Studies have indicated that information is the lifeblood of companies. Feldman and Sherman [7] stated that timely access to critical information separates the winners from the losers in today's information economy. Professionals in most companies too often fail in their quest to obtain the information they need. The amount of time wasted in futile searching for vital information is enormous, leading to staggering cots to the enterprise. It is therefore important for business professionals that they improve their information finding skills to be able to keep them updated about new knowledge in their respective areas of responsibility.

The study participants were asked to indicate how they looked for information once need for information was recognized - what did they do to find the information. The top ten approaches used by business professionals in this study are given in Table 1.

As shown in Table 1, searching websites and browsing company sites are among the top strategies for initiating information finding exercises for business professionals.

Various previous studies, e.g., Choo et al, [8]; Chaudhry [9] reported that professionals in different sectors chose search engines and web sites as their preferred means for finding information. Business professionals in this study also reported use of these channels as their preferred approaches. Surprisingly, personal documents were not considered a starting step for finding information. Similarly, libraries \& information centers and chambers of commerce \& industry were also listed as the leased preferred approaches. This may be either a reflection of unawareness about the valuable resources that could be accessed through these two means or a reflection on the capability of marketing by these two institutions.

Table 1. Information Finding Approaches

\begin{tabular}{|l|l|}
\hline$\#$ & Approach \\
\hline 1 & Search internet (websites, repositories) \\
\hline 2 & Browse company sites (intranets, portals) \\
\hline 3 & Look through personal documents \\
\hline 4 & Examine internal studies (reports) \\
\hline 5 & Consult colleagues (financial consultants) \\
\hline 6 & Scan newspapers and industry magazines \\
\hline 7 & Review reports from competitors \\
\hline 8 & Search relevant research databases \\
\hline 9 & Check Chamber of Commerce sources \\
\hline 10 & Visit library and information centers \\
\hline
\end{tabular}

Some participants reported that they would browse and read relevant industry and trade journals before consulting other means. They also mentioned that many business professionals focus on Big4 knowledge database. Also, they consult more relevant industry practices and international trade journals. This is done because local information agencies prefer to escalate the actual underlying information.

In general, business professionals who participated in this study were confident about their information finding skills. When asked in what areas they would like to develop their information finding (searching) skills, $61.54 \%$ chose electronic database searching and $38.46 \%$ indicated internet searching. Participants also mentioned that there was a need to improve information finding and use skills in the areas of libraries, company websites, trade journals, and better familiarity with specific sources such as Bloomberg. Need for training on information searching and courses for information literacy at work were also identified by earlier information behavior studies in Kuwait: Chaudhry and Al-Ansari [10] Chaudhry, Rehman, and Al-Sugair [11] Chaudhry and Al-Mahmood [12].

\subsection{Preferred Information Sources}

The participants were asked to rate the frequently used information sources considering relevance, access, ease of use, accuracy and currency. We selected these factors based on the best practices of libraries and information centers for reviewing the quality of information sources. The top 10 sources reported by the participants are listed in Table 2. 
Table 2. Preferred Information Sources

\begin{tabular}{|c|l|}
\hline$\#$ & Source \\
\hline 1 & Websites \\
\hline 2 & Analysts reports \\
\hline 3 & Business information sources \\
\hline 4 & Industry journals \\
\hline 5 & Financial consultants \\
\hline 6 & Personal documents \\
\hline 7 & Libraries and information centers \\
\hline 8 & Sources from Chambers of Commerce \\
\hline 9 & Blogs \\
\hline 10 & Social media \\
\hline
\end{tabular}

Websites, analyst reports, and business information services were considered the top three sources of information useful in seeking information to support financial activities and decisions. Since most newspapers and industry magazines are available online, it is quite natural that business professionals considered these as important. Financial consultants were considered important human sources of information.

Business professionals, who participated in this study, also listed some specific sources they use. These include Bloomberg, Reuter and Zawya. Bloomberg and Reuters are international in scope while Zawya provides financial analysis and news with the Arab world perspective. The following newspapers were considered of high quality for obtaining business information:

- Financial Times

- Morning Star

- Hamming Star

The participants also reported that the following special sources were important for their work:

- KSE.com

- Mubasher.com

- Argam

\subsection{Use of Social Media}

Social media has changed the information landscape and opened up new opportunities for professional development and continuing education. The participants of this study frequently used social media for keeping them updated in their areas of responsibility. Most frequently used social media are listed in Table 3.

As shown in Table 3, business professionals most frequently used wikis and blogs and LinkedIn, Twitter, and Facebook. The other two social media reported included WhatsApp and Instagram.

McMillan [13] reported that U.S. regulatory authorities caution professionals and advise a careful and restraint use of social media by business professionals.
Table 3. Social Media Used

\begin{tabular}{|c|l|}
\hline$\#$ & Media \& Software \\
\hline 1 & Wikis \\
\hline 2 & Blogs \\
\hline 3 & LinkedIn \\
\hline 4 & Twitter \\
\hline 5 & Facebook \\
\hline
\end{tabular}

This could be because of the competitive nature of the work of financial professionals. This finding indicates that attention needs to be paid to improve information organization and management on mobile devices and steps need to be taken to improve personal information management among these professionals to exploit the potential of social media.

\subsection{Identification of Contacts}

Social media allow professionals to identify relevant contacts and build personal networks that are expected to be helpful in learning and therefore in professional development. Professionals in different sectors identify personal contacts from social networking services to support personal networks. They collect and compile information about those contacts that have expertise in their area of responsibility. They prefer to follow up with those contacts whose work they admire.

Schawbel [14] suggests a set of activities that help organize contact to turn into personal networks. $\mathrm{He}$ suggests to record at least three things about contacts identified: what company they work for, their location, and their contact information. By organizing your contacts under categories will allow to reconnect with the right people, and expand your relationships.

Business professionals who participated in this study were also active in identifying contact and building personal networks. Five activities were considered particularly important in this regards. These are listed in Table 4.

Table 4. Building Personal Networks

\begin{tabular}{|l|l|}
\hline$\#$ & \multicolumn{1}{|c|}{ Activity } \\
\hline 1 & $\begin{array}{l}\text { Identify personal contacts from email and } \\
\text { social media. }\end{array}$ \\
\hline 2 & $\begin{array}{l}\text { Maintain updated lists of contacts with } \\
\text { relevant details using networking sites. }\end{array}$ \\
\hline 3 & $\begin{array}{l}\text { Try to access networks of professional } \\
\text { contacts. }\end{array}$ \\
\hline 4 & $\begin{array}{l}\text { Look for people with similar interests on } \\
\text { social networks. }\end{array}$ \\
\hline 5 & $\begin{array}{l}\text { Review frequency of interaction of } \\
\text { professional contacts. }\end{array}$ \\
\hline
\end{tabular}


As shown in Table 4, email and social media played an important role in identifying professional contacts. Business professionals also gave importance to collect sufficient contact details and access personal networks of their contact to build personal networks and strengthen professional relationships.

Razmerita, Kirchner, and Sudzina [15] have suggested that personal networks could reconcile the conflicting interests of managing organizational knowledge with personal objectives. They also suggested that these tools facilitate a more effective way of sharing and managing knowledge at a personal level. In their opinion, social software plays a multifaceted role in communicating, collaborating, sharing, and managing knowledge.

\subsection{Using Personal Networks for Learning}

Building a network of colleagues is helpful in seeking and finding knowledge, professional development and continuing education. Personal networks not only allow us to gather information but also push information to us from trusted sources. Business professionals need to take time to reflect upon what they have learnt. Blogs and other online self-publishing tools are powerful means for steps need to be taken to create more awareness about the importance of these activities and personal networks in enhancing learning.

\section{Table 5. Using Networks for Learning}

\begin{tabular}{|c|l|}
\hline$\#$ & \multicolumn{1}{|c|}{ Activity } \\
\hline 1 & $\begin{array}{l}\text { Communicate regularly with their contacts } \\
\text { (with similar expertise) in the network. }\end{array}$ \\
\hline 2 & $\begin{array}{l}\text { Follow those people whose work is admired } \\
\text { on networks. }\end{array}$ \\
\hline 3 & $\begin{array}{l}\text { Try to gain access to networks of their } \\
\text { professional contacts. }\end{array}$ \\
\hline 4 & $\begin{array}{l}\text { Follow people that their contacts enjoy } \\
\text { reading or following. }\end{array}$ \\
\hline 5 & $\begin{array}{l}\text { Re-tweet to contacts on Twitter and browse } \\
\text { their tags. }\end{array}$ \\
\hline 6 & $\begin{array}{l}\text { Share information on social network sites } \\
\text { (LinkedIn and Facebook). }\end{array}$ \\
\hline 7 & $\begin{array}{l}\text { Respond to comments on blogs and reflect } \\
\text { on wiki edits of experts in personal } \\
\text { networks. }\end{array}$ \\
\hline 8 & $\begin{array}{l}\text { Make comments \& reflect on postings of } \\
\text { selected contacts. }\end{array}$ \\
\hline
\end{tabular}

As shown in Table 5, business professionals considered communication and information sharing with contact in their networks. They commented on blogs and responded to others comments on their postings. There is a need to place more emphasis on collaborative learning through social bookmarks, reflecting and commenting on blogs, and editing wikis to provide effective support for to continuing education and professional development.

The participants reported that they tried to have regular communication with contacts that have expertise in their area of responsibility. Similarly, a large number of respondents indicated that they considered it very important to follow up with contacts whose work they admired. Business professionals who participated in this study appreciated these activities focusing on contacts' networks were considered very important. Activities indicated by the participants are in line with the trends reported in existing literature.

Spiglanin [16] states that various social platforms provide short-form blogging, threaded discussions, link sharing, and a number of other social media services These social platforms offer different types of relationships (friends on Facebook, followers on Twitter, etc.) and may serve as nodes on several social and workplace networks. Discussions in interviews with officers at the ministry revealed that they did not use these facilities frequently enough to strengthen their personal networks. These services offer a great opportunity for supporting self-directed learning and professional development in business organizations. Christakis and Fowler [17] observed that professionals were tied to the behavior and sources of knowledge of those with whom they interacted. These interactions include subscribing to and commenting on others' blogs and information on social network sites such as LinkedIn and Facebook.

Perceptions and practices of business professionals who participated in this study appear to be in line with the findings of earlier studies. Communication with contacts, following likeminded people, gaining access to networks of professional contact, and following people on networks were the five top activities they reported for strengthening their personal networks.

\section{Lessons Learnt}

Efficiency in information finding and knowledge of relevant sources are important for information literacy at work. Business professionals use different approaches to stay informed. Information on companies, countries, and investment opportunities is considered most important for continuing education and professional development. Preferred sources of information include internal reports, consulting with colleagues, and websites. Business professionals considered some specific business sources important for their continuing education. These include newspapers such as Financial Times, Morning Star, and Hamming Star. Business information sources such as Bloomberg, Reuters, and Zahawya. In addition to the specific sources, company websites, legal colleagues, and stock exchange are among the first choice for 
keeping updated in relevant business fields. Personal documents, libraries and information centers, and sources from chambers of commerce do not appear to be preferred for finding information by business professionals. Business organizations need to create more awareness about these valuable resources.

Business professionals consider information finding as an important element of their professional development. They feel that training in searching databases will enhance their information finding skills and improve information literacy at work. Improved literacy at work is considered important for professional development and organization effectiveness.

Identification of contacts and building and maintaining personal networks are important for professional development. Professionals in business enterprises consider it important to follow up with contacts whose work they admire. They also consider the networks of their contacts very important. They perceive that active participation on social media can help strengthen personal networks. They regularly comment on postings and reflect on Blogs \& Wikis to turn their personal networks into learning networks. Business professionals are of the opinion that collaboration with experts in other companies facilitates access to information sources for keeping knowledge up to date. While they are conscious of competition, business professionals also give importance to build partnerships and alliances. Business professionals would be able to fully utilize their social networks and strengthen their learning networks if they contributed to blogs and wikis about appropriate activities in their personal networks.

This study provided useful data on building personal networks and using these networks to support professional development and continuing education. Further research is desirable to enhance understanding and develop insights for strengthening learning networks by active participation on these networks. Richer data may be obtained with the use of qualitative methods, e.g., group discussions and expanding the sample to include participants from several sectors.

\section{References}

[1] Aldridge, F, and Hughes, D. (2012). Adult participation in learning survey. Leicester, UK, National Institute of Adult Continuing Education (NIACE). http://shop.niace.org.u $\mathrm{k} /$ media/catalog/product/n/i/niaceparticipationsurvey 2012 . pdf (Access date: 5 January 2016).

[2] Manning, G. (2007). Self-directed learning: A key component of adult learning theory. Business and Public Administration Studies, 2(2).

[3] Candy, P. (1997). Self-Direction for Lifelong Learning. San Francisco: Jossey-Bass, 1991. p.15
[4] Cross, R. Social networks: Personal networks and leadership development, https://www.leader-values.com/a rticle.php?aid=633 (Access date: 27 July 2016).

[5] Anklam, P. Leveraging context, knowledge, and networks, Personal Network Management KM Forum. Boston, MA. http://www.slideshare.net/panklam/personalnetwork-management-km-forum-oct-2009 (Access date: 27 July 2016).

[6] Chaudhry, A. (2013). Information management strategies of knowledge workers in the public sector in Kuwait, Libri: International Journal of Libraries and Information Services, 63(2).

[7] Feldman, S and Sherman, C. The High Cost of Not Finding Information: An IDC White Paper. http://www.ej itime.com/materials/IDC\%20on\%20The\%20High\%20Cost $\% 200$ \%20Not\%20Finding\%20Information.pdf (Access date: 10 January 2016).

[8] Choo, C. W., Detlor, B., and Turnbull, D. (2000). Web Work: Information Seeking and Knowledge Work on the World Wide Web. Dordrecht, the Netherlands: Kluwer Academic Publishers.

[9] Chaudhry, A. (2014). Leveraging personal networks for strengthening personal knowledge management, Libri: International Journal of Libraries and Information Services, 64(4).

[10] Chaudhry, A and Al-Ansary, H. (2013). Use of digital and electronicinformation by investment professionals in Kuwait, Library Review, 62(3).

[11] Chaudhry, A., Sajjad, R, and and Al-Sughair, L. (2015). Personal information management practices in the Kuwaiti corporate sector, Malaysian Journal of Library and Information Science, 20(3).

[12] Chaudhry, A and Al-Mahmood, S. (2015). Information literacy at work: A study of information management behavior of Kuwaiti engineers, Electronic Library, 33(2).

[13] McMillan, M. (2012). Ethics and social media: Four key considerations for investment professionals. Enterprising Investor http://blogs.cfainstitute.org/investor /2012/07/26/ethics-and-social-media-4-things-investmentprofessionals-and-firms-should-think-about-before-using-s -ocial-media/ (Access date: 10 January 2016).

[14] Schawbel, D. (2010). How to organize your contacts for networking success? http://mashable.com/2010/06/03/ how-to-organize-contacts/\#enO.2XehUuqp (Access date: 27 July 2016).

[15] Razmerita, L., K. Kirchner, and F. Sudzina. (2009). Personal knowledge management: The role of Web 2.0 tools for managing knowledge at individual and organizational Levels. Online Information Review, 33 (6): 1021-1039.

[16] Spiglanin, T. (2012). Personal knowledge manageme$\mathrm{nt}$ for the workplace professional. Workplace Learning: 
An Insider's Perspective(blog] http://tom.johnandrew rankin.com/?p=1897 (Access date: 5 January 2016).

[17] Christakis, N., and J. Fowler. (2009). Connected: The surprising power of our social networks and how they shape our lives. New York: Little Brown. http://www.con nectedthebook.com/pdf/excerpt.pdf (Access date: 5 January 2016). 